\title{
INDUKCIJA RIZOGENEZE KOD CRNE RIBIZLE (RIBES NIGRUM L.)*
}

\section{Risogenesis Induction of Black currant (Ribes nigrum L.)}

\author{
Neira Omerhodžićc ${ }^{1}$, Safer Međedović ${ }^{2}$, Fatima Pustahija ${ }^{2}$
}

\begin{abstract}
This study elaborates the risogenesis induction of black currant, and possibility of its mass production by means of vegetative reproduction, with usage of ripe cuttings. Furthermore, we presented the influence of the affected cuttings and different hormonal treatments on the risogenesis induction, on a number of cuttings and on the quality of the root system (length and thickness of the lateral roots and the number of second line roots). The cuttings were treated with three types of plant hormones (IAA, IBA, and NAA) in the mould form, in addition to the control group, without hormonal treatment. The cuttings were raised in containers, in a mixture of the substrate of sphagnum and sand, in 3:1 ratio. From the denominated results, the best hormonal treatment for risogenesis induction of black currant was with IAA for the affected cuttings, which coincides with the results reported by other researches.
\end{abstract}

Kev words: Ribes nigrum L., plant hormones, root, affected cutting, cuttings, rizogenesis.

\section{Izvod}

U ovoj studiji je razrađena indukcija rizogeneze kod crne ribizle, odnosno prikazana mogućnost njene masovne proizvodnje vegetativnim putem pomoću zrelih reznica. Također, prikazan je uticaj povrede reznice $\mathrm{i}$ hormonalnog tretmana na sam proces indukcije rizogeneze, na broj ožiljenih reznica kao i kvalitet korjenovog sistema (dužina i debljina bočnih korjenova te broj korjenova II reda). Reznice su tretirane sa tri tipa biljnih hormona (IAA, IBA i NAA) u praškastoj formi i kao dodatak kontrolna grupa, reznice bez hormonalnog tretmana. Reznice su uzgajane u kontejnerima sa supstratom od treseta i riječnog pijeska u odnosu 3:1. Iz navedenih rezultata najbolji hormonalni tretman za indukciju rizogeneze crne ribizle se pokazao IAA, i to kod reznica sa povredom što se podudara sa dostupnim podacima drugih istraživača.

\footnotetext{
* Rad prezentiran na međunarodnoj naučnoj Konferenciji "Šumarska nauka između ekonomije i zahtjeva društva", povodom 60. godišnjice Šumarskog fakulta Univerziteta u Sarajevu, Sarajevo, hotel "Hollywood" 8 - 10.10.2008. godine

${ }^{1}$ Student Master studija Šumarskog fakulteta Univerziteta u Sarajevu -

2 Šumarski Fakultet Univerzitet u Sarajevu - Faculty of forestry University of Sarajevo
} 
Ključne riječi: Ribes nigrum L, biljni hormoni, korijen, povreda reznice, reznice, rizogeneza.

\section{UVOD - Introduction}

Razmnožavanje je univerzalna osobina svih živih organizama da u novim generacijama osiguraju sebi slične ili iste potomke, jer život u osnovi počiva na temeljnom principu sposobnosti reprodukcije živih sistema.

Osobine promjenljivosti vrste koje su izazvane različitim mutacijama (dekorativnost cvijeta, lista, oblika krošnje, otpornosti prema bolestima, mrazu, suši, naglašenom prirastu) teško je sačuvati generativnim razmnožavanjem, odnosno njihovo fiksiranje i prijenos na nove generacije potomaka jedino je moguće održati postupcima vegetativnog razmnožavanja.

$\mathrm{U}$ tehnologiji proizvodnje sadnica najčešćim načinom vegetativnog razmnožavanja - ožiljavanjem reznica postoji veliki broj ograničavajućih faktora, koji u krajnjem ishodu mogu predstavljati ograničavajući faktor rizogeneze. Među njima presudnu ulogu imaju:

- dužina reznice,

- $\quad$ starost reznice i matičnog stabla,

- $\quad$ vrijeme uzimanja reznica,

- fiziološki tretmani,

- $\quad$ povreda reznica,

- $\quad$ prihranjivanje reznica,

- $\quad$ primjena sredstava zaštite,

- $\quad$ tipovi podloga za ožiljavanje reznica i

- $\quad$ sistem za orošavanje.

Ribizla (ar. ribas - kiseli okus; sl. 1) iz porodice Grossulariaceae, višegodišnja je grmasta biljka čiji je životni vijek obično 15 godina, a koja obuhvata oko 150 , većinom listopadnih, vrsta grmlja u sjevernoj umjerenoj zoni i na Andima.

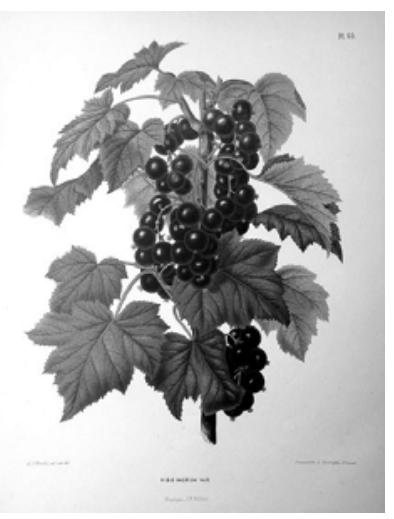

Slika 1. Ribes nigrum L.

Ribizle su postale vrlo omiljene pošto mlade biljke brzo rastu, a mogu se primjenjivati u hortikulturi na različite načine zbog njihovog bogatstva sa različitim dekorativnim svojstvima, a svoju primjenu u vrtu nalaze i kao jagodičasto voće.

Crna ribizla je grm koji dostiže $1,5-2 \mathrm{~m}$ visine, a širinu i do 2,5 m. Porijeklom je iz Sjeverne Europe i Sjeverne Azije. Često je u prirodi susrećemo zajedno sa Salix petandra, Alnus glutinosa i Betula pubescens (JOVANOVIĆ, 2000).

Plod crne ribizle ima veliku hranljivu, ljekovitu i dekorativnu vrijednost, a njeni listovi s donje strane imaju uljne žlijezde, te se često dodaju u čaj i alkohol (vodku). 


\section{CILJ I ZADACI ISTRAŽIVANJA - The objective and the task of the study}

U ovoj studiji smo imali za cilj razraditi metode indukcije rizogeneze kod crne ribizle (Ribes nigrum L.), odnosno mogućnost njene masovne proizvodnje vegetativnim putem pomoću zrelih reznica.

Zadatak rada je bio da se pokaže uticaj povrede reznice i hormonalnog tretmana na sam proces ožiljavanja, na broj ožiljenih reznica kao i na njihov kvalitet, odnosno na kvalitet korjenovog sistema (dužina, debljina bočnih korjenova i broj korjenova drugog reda).

\section{MATERIJAL I METODE RADA - Material and Methods}

Početkom aprila 2008. godine prikupljeno je 110 zrelih reznica crne ribizle, sa privatne plantaže, različite dužine $(11,5$ do $24,5 \mathrm{~cm})$. Kao induktorima rizogeneze, reznice su tretirane sa tri tipa biljnih hormona (IAA, IBA, NAA) u praškastoj formi, dok dio reznica nije uopće tretiran i predstavljao je kontrolni uzorak.

U cilju pripremanja hormonalnih smjesa za tretiranje reznica smo odmjerili po $200 \mathrm{mg}$ sva tri hormona (IAA, IBA, NAA; marke Lacstan) na preciznoj vagi, zatim je svaki posebno rastvoren u $3 \mathrm{ml}$ metanola. $U$ ovako pripremljene rastvore smo, zasebno, dodali po $100 \mathrm{~g}$ talk pudera (PA) i $200 \mathrm{mg}$ zaštitne materije (fungicida), te ostavili da evaporira na sobnoj temperaturi narednih dva sata u zamračenim uslovima. Tokom ovog perioda smjese su se periodično homogenizirale mješanjem sa staklenim štapićem. Nakon toga, smjese su pohranjene u tamne staklene posude, na sobnoj temperaturi.

U sljedećoj fazi eksperimenta se na 55 reznica, od ukupnih 110, izvršilo povrjeđivanje floemskog dijela u dužini od $1,5 \mathrm{~cm}$ od baze reznice (u jednom potezu noža, skinut je floemski dio kore), dok je preostalih 55 reznica ostalo nepovrjeđeno. Tri grupe reznica od po 30 individua ( 15 sa povredom i 15 bez povrede) tretirani su sa različitim biljnim hormonima (IAA, IBA, NAA), dok je kontrolna grupa, bez hormonalnog tretmana, brojila 20 reznica (10 sa povredom i 10 bez povrede).

$\mathrm{Na}$ odabranoj lokaciji je napravljen priručni plastenik veličine $2 \times 1 \mathrm{~m}^{2}$, gdje su uneseni kontejneri sa supstratom od treseta i riječnog pijeska u odnosu 3:1.

Svakih pet dana je iz podloge vađeno po pet reznica slučajnim uzorkom i provjeravan status početka kalusiranja i probijanja korijena.

Kao parametri kvaliteta korjenovog sistema ožiljenih reznica praćeni su: dužina bočnih korjenova, debljina bočnih korjenova i broj korjenova II reda, a za ova mjerenja korišteni su lenjir (tačnosti $\pm 0,1 \mathrm{~cm}$ ) i nonijus (tačnosti $\pm 0,1 \mathrm{~mm}$ ).

$\mathrm{Za}$ rezultate dobivene tokom ovog istraživanja izračunati su osnovni statistički parametri (aritmetička sredina, standardna devijacija, koeficijent varijabilnosti i koeficijent korelacije) primjenom standardnih statističkih metoda analize varijanse (ANOVA) i multiplih testova (LSD) uz korištenje programa Microsoft Excel 2000 i Statistica 5.0. 


\section{REZULTATI I DISKUSIJA - The results and discussion}

Istraživanjem uticaja pojedinih hormona $\mathrm{i}$ povrede reznice na indukciju rizogeneze i kvalitet korijena ožiljenih reznica kod crne ribizle (Ribes nigrum L.), utvrđeno je postojanje varijabilnosti između ožiljenih reznica tretiranih istim tretmanom i reznica tretranih različitim tretmanima (IAA, IBA, NAA. i bez hormonalnih tretmana).

Pri redovnom pregledanju reznica zamjećeno je da se nakon 15 dana pojavilo kalusno tkivo na prerezanom dijelu stabla reznica $i$ to $u$ zoni nanošenja aktivne materije. Iako je kod reznica na poziciji nanesenog hormona dolazilo do intezivnog dijeljenja i povećanja volumena tkiva floema, ipak su se prvi korjenovi javili na mjestima lisnih ožiljaka prvog i drugog reda listova, i to u odnosu na bazu reznice (dio reznice koji je bio uronjen u podlogu).

Nakon 25 dana konstatovali smo prvo probijanje korijena kod reznica sa hormonalnim tretmanom, dok su reznice bez hormona u odnosu na njih kasnile za oko 10 dana sa formiranjem korijenja. Novonastali korjenov sistem se karakterisao odsustvom glavnog korijena, ali i prisustvom razgranatog i bogatog bočnog korijenja (tabla 1).

A

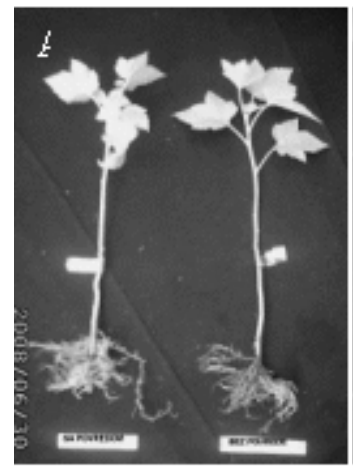

$\mathrm{B}$

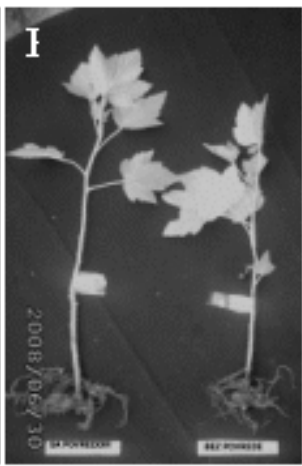

$\mathrm{C}$

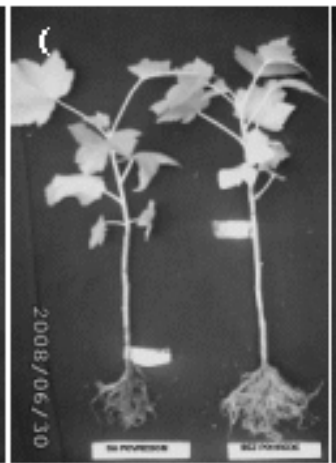

$\mathrm{D}$

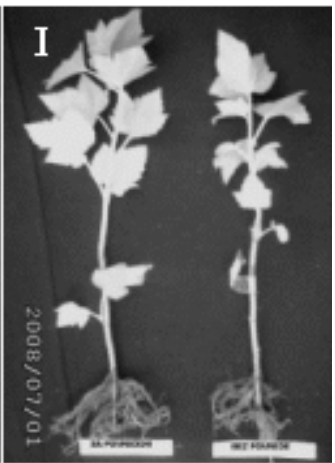

Slika 2. Reznice crne ribizle tretirane razilčitim hormonalnim tretmanima (A-sa IAA; Bsa IBA; C-sa NAA; D-bez hormona)

Figure 1.Cuttings of black current treated with different hormonal treatment (A-with IAA; $B$-with IBA; $C$-with NAA; D- without hormones)

Nakon tri mjeseca od početka izvođenja eksperimenta, kada je izvršena finalna provjera korjenovog sistema svih pojedinačnih reznica, procenat ožiljavanja je iznosio $100 \%$, i to bez obzira da li se primijenio neki hormonalni tretman ili ne.

Prema ovom postotku ožiljenih reznica možemo reći da ribizla pripada vrstama visoke regenerativne i reperativne sposobnosti, te da se sadnice ribizle mogu proizvoditi i bez hormonalnog tretmana, samo što se njihov korjenov sistem sporije i slabije razvija. 
Iako povreda reznice ne predstavlja presudan faktor za indukciju rizogeneze kod crne ribizle, korjenovi koji su se razvili kod povrijeđenih reznica imali su kvalitativno i kvantitativno bolji korjenov sistem, u odnosu na nepovrijeđene reznice (tabla 1).

Za sagledavanje varijabilnosti između ožiljenih reznica (sa povredom ili bez povrede) tretiranih istim hormonom u uzorku od osam tretmana, nakon obavljene statističko-varijacijske analize, kao najpogodnija mjera uzet je koeficijent varijabilnosti. Raspon vrijednosti ovog koeficijenta (ukupni uzorak) za dužinu bočnih korjenova reznica se kretao od 19,480 do 78,572\%; za debljinu bočnih korjenova od 12,622 do $123,076 \%$; te za broj korjenova drugog reda svake jedinke od 34,998 do $138,306 \%$ (tabele 1,2 i 3 ).

U daljim istraživanjima pokušali smo utvrditi odnose koji vladaju između reznica tretranih različitim tretmanima (IAA, IBA, NAA i bez hormonalnog dodatka).

$\mathrm{Na}$ temelju rezultata dobivenih mjerenjima već spomenutih parametara, uočava se kako postoji razlika u vrijednostima aritmetičkih sredina uspoređivanih svojstava između različitih hormonalnih tretmana i kontrole. Komparacija odnosa aritmetičkih sredina za pojedina istraživana svojstva može se vidjeti na grafikonima 1a, 1b i 1c, dok se komparacija koeficijenata varijabilnosti istraživanih karaktera može vidjeti na grafikonima $1 b, 2 b$ i $3 b$.

Vrijednost aritmetičke sredine za svojstvo dužine bočnih korjenova je najveća u hormonalnom tretmanu sa IAA, i to kod reznica sa povredom gdje iznosi $7,251 \mathrm{~cm}$; dok je najmanja vrijednost $u$ hormonalnom tretmanu sa NAA kod reznica bez povrede, gdje iznosi 4,019 $\mathrm{cm}$ (tabela 1, grafikon 1a).

Za svojstvo debljine bočnih korjenova najveća je vrijednost aritmetičke sredine $\mathrm{u}$ hormonalnom tretmanu aktivnom materijom NAA kod reznica sa povredom i iznosi $0,793 \mathrm{~mm}$. Najmanja je vrijednost u kontrolnoj grupi reznica bez povrede, a iznosi $0,272 \mathrm{~mm}$ (tabela 2 i grafikon 2a).

Najveća vrijednost aritmetičke sredine za svojstvo broja korjenova drugog reda zabilježena je kod opitne grupe sa hormonalnim tretmanom aktivnom materijom IAA kod reznica sa povredom, a najmanja u kontrolnoj grupi reznica bez povrede - (tabela 3 , grafikon 3a).

Kao najbolji za indukciju rizogeneze crne ribizle pokazao se hormonalni tretman sa IAA, i to kod reznica sa povredom, što se podudara sa dostupnim podacima drugih istraživača (MEKIĆ, 1998; MEĐEDOVIĆ, 2003 )

Analizom varijanse (ANOVA) utvrđene su značajne razlike između istraživanih jedinki. Pomoću Fisherovih multiplih testova (LSD), za svaki hormonalni tretman pojedinačno, konstatirano je postojanje statistički značajnih razlika između pojedinih jedinki na objema razinama značajnosti $(\mathrm{p}<0,05$ i $\mathrm{p}<0,01)$. Sve to ukazuje na izraženu varijabilnost kvaliteta ožiljenih reznica uslijed tretiranja različitim hormonalnim tretmanima (IAA, IBA, NAA, bez hormona). 


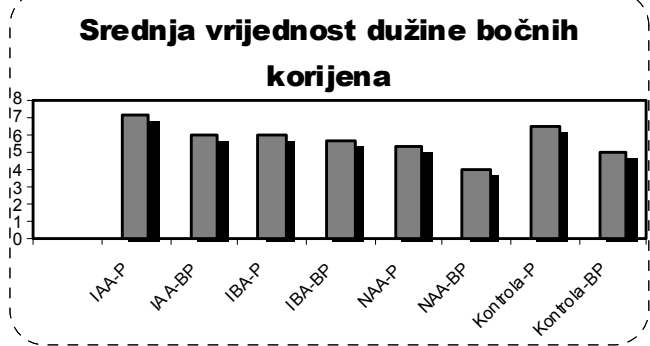

Grafikon 1a. Srednja vrijednost dužine bočnih korjenova

Graf. 1a. Mean value of length of lateral roots

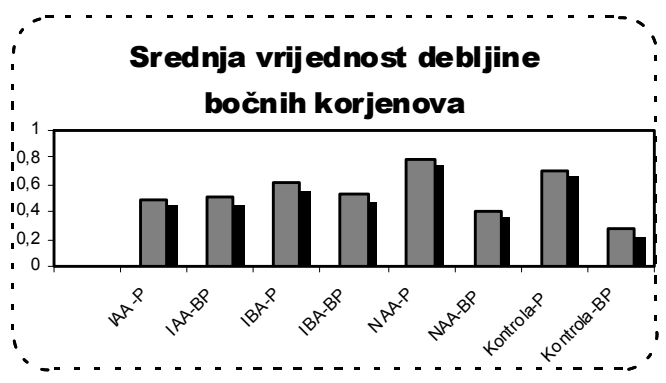

Grafikon 2a. Srednja vrijednost debljine bočnih korjenova

Graf. 2a. Mean value of thickness of lateral roots

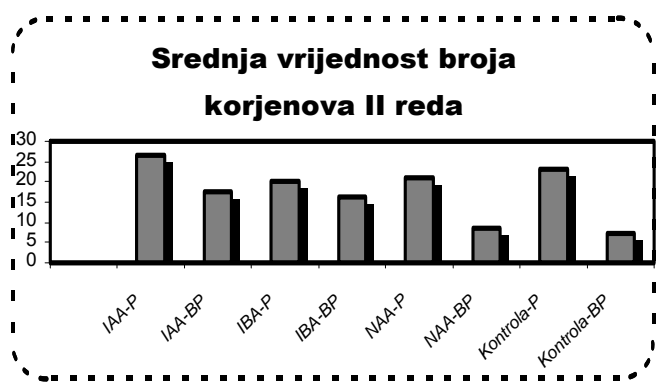

Grafikon 3a. Srednja vrijednost broja korjenova drugog reda

Graf. 3a. Mean value of number of second line roots
Koeficient varij abilnosti dužine bočnih korjenova

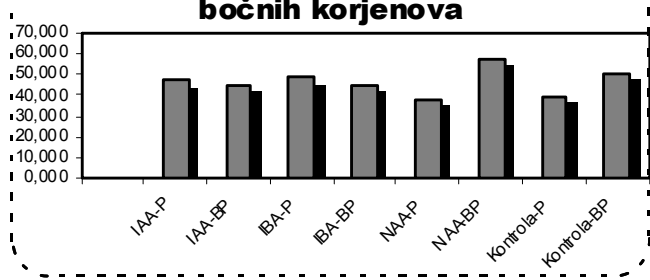

Grafikon 1b. Koeficijent varijabilnosti za dužinu bočnih korjenova

Graf. 1b. Coefficient of variation of length of lateral roots

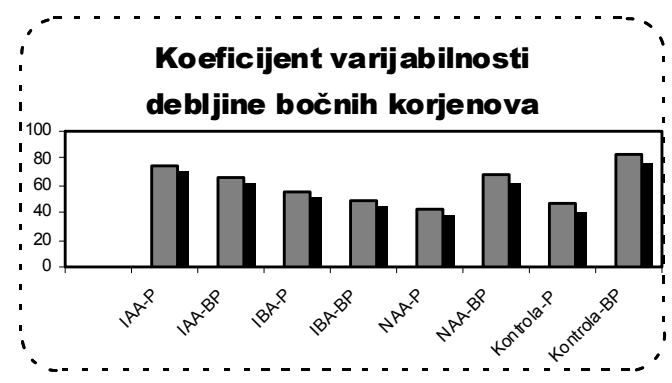

Grafikon 2b. Koeficijenti varijabilnosti za debljinu bočnih korjenova

Graf. 2b. Coefficient of variation of thickness of lateral roots

Koeficijent varijabilnosti broja korjenova II reda

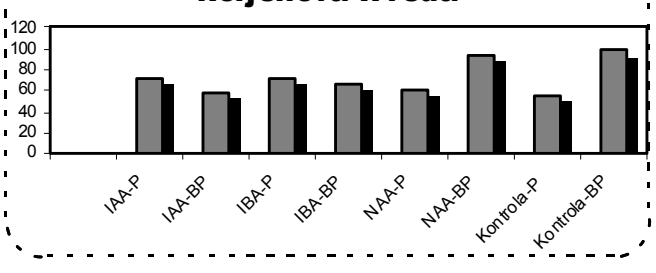

Grafikon 3b. Koeficijenati varijabilnosti broja korjenova drugog reda Graf. 3b. Coefficient of variation of number of second line roots 
Tabela 1. Rezultati mjerenja dužine bočnih korjenova za svaku jedinku (sa povredom ili bez povrede), Table 1. Results of the measuring of the length of lateral roots for each unit (with and without harm).

\begin{tabular}{|c|c|c|c|c|c|c|c|}
\hline & nan & $\begin{array}{l}\text { R br. } \\
\text { sadnice }\end{array}$ & Min. & Max. & Aritm. sred. & Stand. dev. & Koef. varijab. \\
\hline & & 1 & 1 & 10.5 & 5.670 & 2.333 & 41.153 \\
\hline & & 2 & 3 & 20 & 7.164 & 3.741 & 52.223 \\
\hline & 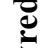 & 3 & 3 & 10 & 6.375 & 2.466 & 38.676 \\
\hline & $\frac{2}{5}$ & 4 & 2 & 21.5 & 6.240 & 4.009 & 64.254 \\
\hline & & 5 & 3.5 & 13 & 8.492 & 2.661 & 31.336 \\
\hline$\Xi$ & & 1 & 1.5 & 12.5 & 4.495 & 2.876 & 63.985 \\
\hline & & 2 & 1.5 & 10 & 4.617 & 2.194 & 47.515 \\
\hline & 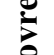 & 3 & 1.5 & 16 & 6.824 & 3.194 & 46.813 \\
\hline & ฮั & 4 & 1.5 & 8 & 5.858 & 1.916 & 32.703 \\
\hline & & 5 & 2.5 & 13 & 7.116 & 3.018 & 42.417 \\
\hline & & 1 & 2 & 14 & 6.481 & 3.109 & 47.962 \\
\hline & & 2 & 2 & 15 & 5.835 & 3.750 & 64.273 \\
\hline & ?ֶ: & 3 & 1 & 16 & 5.141 & 3.244 & 63.093 \\
\hline & $\frac{2}{\pi}$ & 4 & 2.5 & 10.5 & 6.709 & 1.956 & 29.158 \\
\hline & & 5 & 2.5 & 9.8 & 6.463 & 2.082 & 32.211 \\
\hline 光 & & 1 & 1.5 & 10.6 & 6.395 & 2.786 & 43.571 \\
\hline & & 2 & 2.5 & 13.8 & 7.043 & 2.563 & 36.383 \\
\hline & 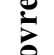 & 3 & 1.5 & 10.5 & 5.500 & 2.813 & 51.139 \\
\hline & $\stackrel{8}{8}$ & 4 & 1.5 & 11.5 & 5.486 & 2.168 & 39.522 \\
\hline & & 5 & 1.5 & 10 & 4.747 & 2.321 & 48.896 \\
\hline
\end{tabular}


Indukcija rizogeneze kod crne ribizle (Ribes nigrum L.)

\begin{tabular}{|c|c|c|c|c|c|c|c|}
\hline \multirow{10}{*}{$\underset{Z}{Z}$} & \multirow{5}{*}{ 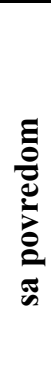 } & 1 & 2.5 & 10.2 & 6.172 & 1.958 & 31.727 \\
\hline & & 2 & 1 & 8 & 4.926 & 1.563 & 31.722 \\
\hline & & 3 & 1.5 & 11.5 & 5.863 & 2.517 & 42.932 \\
\hline & & 4 & 1.5 & 8 & 4.954 & 1.902 & 38.386 \\
\hline & & 5 & 1 & 9.5 & 5.274 & 2.309 & 43.776 \\
\hline & \multirow{5}{*}{ 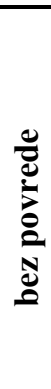 } & 1 & 0.6 & 10.5 & 3.515 & 2.100 & 59.754 \\
\hline & & 2 & 2 & 20.5 & 5.524 & 4.340 & 78.572 \\
\hline & & 3 & 2.3 & 8.5 & 4.451 & 1.683 & 37.820 \\
\hline & & 4 & 1.3 & 7 & 3.411 & 1.769 & 51.858 \\
\hline & & 5 & 1.5 & 8 & 3.879 & 1.551 & 39.996 \\
\hline \multirow{10}{*}{ 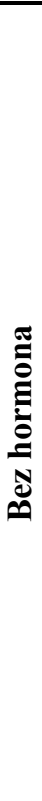 } & \multirow{5}{*}{ 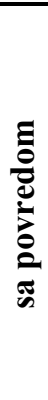 } & 1 & 1 & 13.5 & 6.054 & 2.496 & 41.229 \\
\hline & & 2 & 2.7 & 13 & 5.867 & 2.583 & 44.020 \\
\hline & & 3 & 4 & 12.5 & 8.750 & 2.880 & 32.914 \\
\hline & & 4 & 1 & 11.9 & 7.528 & 2.709 & 35.989 \\
\hline & & 5 & 4 & 7 & 5.610 & 1.093 & 19.480 \\
\hline & \multirow{5}{*}{ 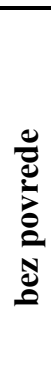 } & 1 & 2.5 & 8 & 5.056 & 1.783 & 35.261 \\
\hline & & 2 & 1.1 & 10.5 & 4.145 & 2.141 & 51.660 \\
\hline & & 3 & 0.5 & 7.3 & 5.290 & 1.946 & 36.783 \\
\hline & & 4 & 1.2 & 14 & 6.090 & 3.204 & 52.610 \\
\hline & & 5 & 1.5 & 11.3 & 5.300 & 3.096 & 58.416 \\
\hline
\end{tabular}


Tabela 2. Rezultati mjerenja debljine bočnih korjenova za svaku jedinku (sa povredom ili bez povrede)

Table 2. Results of the measuring of the thickness of lateral roots of each unit (with or without harm).

\begin{tabular}{|c|c|c|c|c|c|c|c|}
\hline \multicolumn{2}{|c|}{ Tretman } & \multirow{2}{*}{$\begin{array}{c}\begin{array}{c}\text { R br. } \\
\text { sadnice }\end{array} \\
1\end{array}$} & \multirow{2}{*}{$\begin{array}{c}\text { Min. } \\
\text { (mm) } \\
0.2\end{array}$} & \multirow{2}{*}{$\begin{array}{c}\text { Max. } \\
\text { (mm) } \\
0.8\end{array}$} & \multirow{2}{*}{$\begin{array}{c}\begin{array}{c}\text { Aritm. sred. } \\
(\mathbf{m m})\end{array} \\
0.480\end{array}$} & \multirow{2}{*}{$\begin{array}{c}\text { Stand. dev. } \\
0.175\end{array}$} & \multirow{2}{*}{$\begin{array}{c}\text { Koef. varijab. } \\
(\mathbf{\%}) \\
36.483\end{array}$} \\
\hline \multirow{10}{*}{ 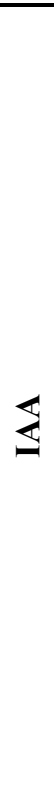 } & \multirow{5}{*}{ 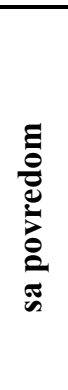 } & & & & & & \\
\hline & & 2 & 0.1 & 0.5 & 0.195 & 0.129 & 66.008 \\
\hline & & 3 & 0.1 & 1.1 & 0.663 & 0.358 & 54.086 \\
\hline & & 4 & 0.1 & 1.2 & 0.280 & 0.218 & 77.837 \\
\hline & & 5 & 0.2 & 2 & 0.658 & 0.403 & 61.299 \\
\hline & \multirow{5}{*}{ 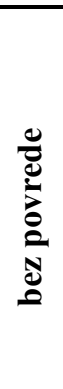 } & 1 & 0.1 & 2 & 0.410 & 0.505 & 123.076 \\
\hline & & 2 & 0.1 & 1 & 0.429 & 0.276 & 64.265 \\
\hline & & 3 & 0.1 & 1.5 & 0.341 & 0.256 & 75.029 \\
\hline & & 4 & 0.3 & 1 & 0.642 & 0.227 & 35.276 \\
\hline & & 5 & 0.3 & 1.9 & 0.711 & 0.474 & 66.659 \\
\hline \multirow{8}{*}{$\underset{\theta}{\mathscr{\theta}}$} & \multirow{5}{*}{ 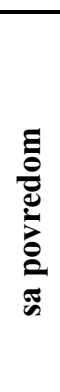 } & 1 & 0.2 & 0.9 & 0.478 & 0.190 & 39.660 \\
\hline & & 2 & 0.3 & 2 & 0.788 & 0.476 & 60.325 \\
\hline & & 3 & 0.1 & 0.8 & 0.397 & 0.201 & 50.652 \\
\hline & & 4 & 0.4 & 1.9 & 0.948 & 0.306 & 32.264 \\
\hline & & 5 & 0.3 & 1 & 0.613 & 0.236 & 38.578 \\
\hline & \multirow{3}{*}{ 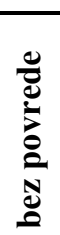 } & 1 & 0.2 & 0.9 & 0.486 & 0.162 & 33.379 \\
\hline & & 2 & 0.3 & 1.2 & 0.839 & 0.237 & 28.233 \\
\hline & & 3 & 0.1 & 0.8 & 0.400 & 0.213 & 53.337 \\
\hline
\end{tabular}


Indukcija rizogeneze kod crne ribizle (Ribes nigrum L.)

\begin{tabular}{|c|c|c|c|c|c|c|c|}
\hline & & 4 & 0.1 & 1 & 0.529 & 0.209 & 39.503 \\
\hline & & 5 & 0.1 & 0.9 & 0.433 & 0.244 & 56.310 \\
\hline \multirow{10}{*}{$\underset{Z}{\mathbb{Z}}$} & \multirow{5}{*}{ 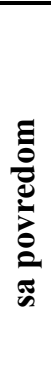 } & 1 & 0.3 & 2.1 & 0.908 & 0.334 & 36.791 \\
\hline & & 2 & 0.1 & 2.2 & 0.859 & 0.372 & 43.290 \\
\hline & & 3 & 0.3 & 1.1 & 0.800 & 0.206 & 25.802 \\
\hline & & 4 & 0.2 & 1.2 & 0.663 & 0.302 & 45.569 \\
\hline & & 5 & 0.2 & 2 & 0.683 & 0.380 & 55.636 \\
\hline & \multirow{5}{*}{ 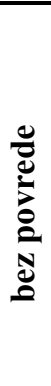 } & 1 & 0.1 & 1 & 0.347 & 0.235 & 67.695 \\
\hline & & 2 & 0.1 & 1 & 0.262 & 0.220 & 84.066 \\
\hline & & 3 & 0.1 & 1 & 0.609 & 0.242 & 39.789 \\
\hline & & 4 & 0.1 & 1.8 & 0.446 & 0.353 & 79.133 \\
\hline & & 5 & 0.1 & 1 & 0.321 & 0.226 & 70.374 \\
\hline \multirow{10}{*}{ 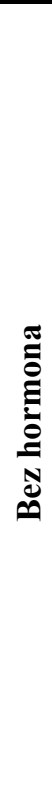 } & \multirow{5}{*}{ 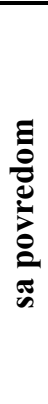 } & 1 & 0.4 & 1 & 0.692 & 0.196 & 28.283 \\
\hline & & 2 & 0.1 & 1.9 & 0.472 & 0.453 & 96.033 \\
\hline & & 3 & 0.8 & 1.1 & 0.988 & 0.125 & 12.622 \\
\hline & & 4 & 0.3 & 1.3 & 0.794 & 0.265 & 33.295 \\
\hline & & 5 & 0.5 & 1.2 & 0.770 & 0.291 & 37.764 \\
\hline & \multirow{5}{*}{ 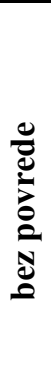 } & 1 & 0.1 & 1.1 & 0.563 & 0.348 & 61.883 \\
\hline & & 2 & 0.1 & 0.6 & 0.237 & 0.126 & 53.246 \\
\hline & & 3 & 0.1 & 0.6 & 0.233 & 0.139 & 59.590 \\
\hline & & 4 & 0.1 & 1.2 & 0.262 & 0.256 & 97.701 \\
\hline & & 5 & 0.1 & 0.4 & 0.174 & 0.092 & 52.635 \\
\hline
\end{tabular}


Tabela 3. Rezultati mjerenja broja korjenova drugog reda za svaku jedinku (sa povredom ili bez povrede)

Table 3. Results of measuring of the number of second line roots of each unit (with or without harm).

\begin{tabular}{|c|c|c|c|c|c|c|c|}
\hline \multicolumn{2}{|c|}{ Tretman } & \multirow{2}{*}{$\begin{array}{c}\text { R br. } \\
\text { sadnice } \\
1\end{array}$} & \multirow{2}{*}{$\begin{array}{c}\text { Min. } \\
2\end{array}$} & \multirow{2}{*}{$\begin{array}{c}\text { Max. } \\
33\end{array}$} & \multirow{2}{*}{$\begin{array}{c}\text { Aritm. sred. } \\
15.800\end{array}$} & \multirow{2}{*}{$\begin{array}{c}\text { Stand. dev. } \\
10.053\end{array}$} & \multirow{2}{*}{$\begin{array}{c}\text { Koef. varijab. } \\
(\%) \\
63.628\end{array}$} \\
\hline \multirow{10}{*}{ 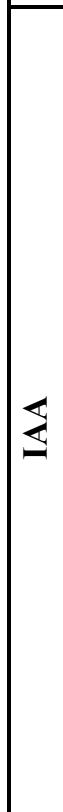 } & \multirow{5}{*}{ 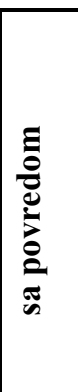 } & & & & & & \\
\hline & & 2 & 0 & 24 & 11.591 & 6.953 & 59.989 \\
\hline & & 3 & 10 & 48 & 31.500 & 12.282 & 38.992 \\
\hline & & 4 & 0 & 88 & 18.800 & 16.985 & 90.347 \\
\hline & & 5 & 3 & 90 & 32.731 & 21.398 & 65.377 \\
\hline & \multirow{5}{*}{ 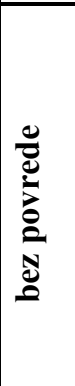 } & 1 & 3 & 76 & 18.350 & 17.907 & 97.586 \\
\hline & & 2 & 2 & 33 & 16.250 & 9.190 & 56.554 \\
\hline & & 3 & 0 & 46 & 17.882 & 11.318 & 63.294 \\
\hline & & 4 & 5 & 34 & 16.038 & 8.077 & 50.360 \\
\hline & & 5 & 6 & 47 & 19.684 & 11.968 & 60.799 \\
\hline \multirow{9}{*}{ 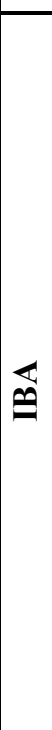 } & \multirow{5}{*}{ 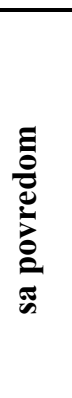 } & 1 & 0 & 73 & 22.969 & 16.059 & 69.918 \\
\hline & & 2 & 0 & 53 & 22.706 & 16.461 & 72.497 \\
\hline & & 3 & 0 & 30 & 9.241 & 5.998 & 64.903 \\
\hline & & 4 & 7 & 51 & 29.217 & 13.457 & 46.058 \\
\hline & & 5 & 5 & 32 & 18.500 & 8.173 & 44.179 \\
\hline & \multirow{4}{*}{\begin{tabular}{l}
0 \\
\multirow{2}{0}{} \\
$\vdots$ \\
0 \\
0 \\
0 \\
0 \\
0
\end{tabular}} & 1 & 3 & 28 & 16.429 & 7.393 & 45.001 \\
\hline & & 2 & 2 & 52 & 21.435 & 12.284 & 57.308 \\
\hline & & 3 & 0 & 47 & 15.567 & 13.423 & 86.231 \\
\hline & & 4 & 1 & 25 & 12.536 & 6.478 & 51.675 \\
\hline
\end{tabular}


Indukcija rizogeneze kod crne ribizle (Ribes nigrum L.)

\begin{tabular}{|c|c|c|c|c|c|c|c|}
\hline & & 5 & 0 & 47 & 15.900 & 10.927 & 68.724 \\
\hline \multirow{10}{*}{$\frac{\mathbb{z}}{z}$} & \multirow{5}{*}{ 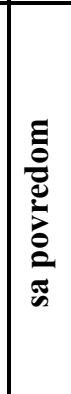 } & 1 & 6 & 68 & 33.840 & 14.848 & 43.878 \\
\hline & & 2 & 0 & 33 & 12.513 & 8.723 & 69.716 \\
\hline & & 3 & 1 & 37 & 21.250 & 8.168 & 38.438 \\
\hline & & 4 & 4 & 39 & 20.792 & 10.168 & 48.905 \\
\hline & & 5 & 2 & 40 & 20.478 & 11.778 & 57.513 \\
\hline & \multirow{5}{*}{ 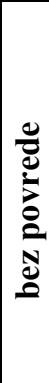 } & 1 & 0 & 27 & 6.483 & 5.765 & 88.923 \\
\hline & & 2 & 0 & 43 & 7.810 & 10.801 & 138.306 \\
\hline & & 3 & 1 & 41 & 14.298 & 10.136 & 70.891 \\
\hline & & 4 & 0 & 28 & 8.643 & 6.528 & 75.525 \\
\hline & & 5 & 0 & 16 & 5.758 & 4.198 & 72.920 \\
\hline \multirow{10}{*}{ 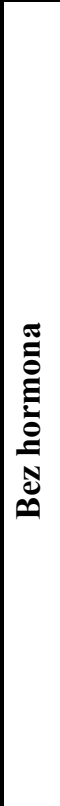 } & \multirow{5}{*}{ 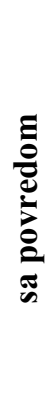 } & 1 & 10 & 47 & 23.192 & 9.728 & 41.947 \\
\hline & & 2 & 0 & 38 & 13.611 & 11.868 & 87.191 \\
\hline & & 3 & 18 & 51 & 28.875 & 10.106 & 34.998 \\
\hline & & 4 & 9 & 53 & 28.111 & 14.311 & 50.909 \\
\hline & & 5 & 12 & 49 & 28.200 & 13.555 & 48.067 \\
\hline & \multirow{5}{*}{ 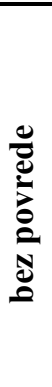 } & 1 & 1 & 38 & 12.750 & 10.247 & 80.368 \\
\hline & & 2 & 0 & 16 & 5.079 & 3.996 & 78.674 \\
\hline & & 3 & 0 & 15 & 4.333 & 4.453 & 102.772 \\
\hline & & 4 & 0 & 32 & 8.810 & 8.773 & 99.583 \\
\hline & & 5 & 1 & 29 & 8.261 & 6.750 & 81.713 \\
\hline
\end{tabular}


Pomoću Fisherovih multiplih testova (LSD), na nivou značajnosti $\mathrm{p}<0,05$ i $\mathrm{p}<0,01$, su predstavljene statistički značajne razlike u dužini bočnih korjenova ožiljenih reznica među podgrupama tretiranih reznica (sa povredom ili bez povrede) i to u okviru grupa tretiranih istim koncentracijama biljnih hormona (tabela 4).

Tabela 4. Statistički značajnih razlike $(\mathrm{p}<0,05 ; \mathrm{p}<0,01)$ dužine bočnih korjenova za svaku istraživanu jedinku (sa povredom i bez povrede)

Table 4. Significant differences $(p<0,05 ; p<0,01)$ in the length of lateral roots of each unit (with or without harm).

\begin{tabular}{|c|c|c|c|c|c|}
\hline Tretman & R br. sadnice & Sadnica 1 & Sadnica 2 & Sadnica 3 & Sadnica 4 \\
\hline \multirow{4}{*}{ 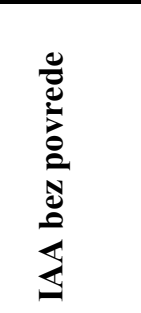 } & Sadnica 2 & 0.5728 & & & \\
\hline & Sadnica 3 & $0.0034 * *$ & $0.0065 * *$ & & \\
\hline & Sadnica 4 & 0.1000 & 0.2113 & 0.1824 & \\
\hline & Sadnica 5 & $0.0037^{* * *}$ & $0.0075 * *$ & 0.7127 & 0.1341 \\
\hline \multirow{4}{*}{ 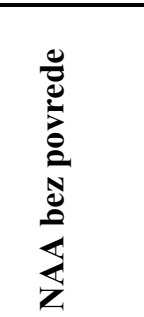 } & Sadnica 2 & $0.0005 * *$ & & & \\
\hline & Sadnica 3 & $0.0338^{*}$ & 0.0705 & & \\
\hline & Sadnica 4 & 0.8395 & $0.0013 * *$ & 0.0540 & \\
\hline & Sadnica 5 & 0.4560 & $0.0094 * *$ & 0.2635 & 0.4185 \\
\hline \multirow{4}{*}{ 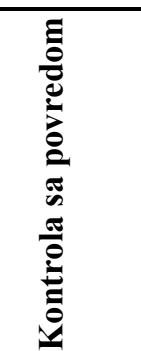 } & Sadnica 2 & 0.8065 & & & \\
\hline & Sadnica 3 & $0.0089 * *$ & $0.0078 * *$ & & \\
\hline & Sadnica 4 & 0.0567 & 0.0484* & 0.2505 & \\
\hline & Sadnica 5 & 0.6325 & 0.7940 & $0.0094 * *$ & 0.0540 \\
\hline
\end{tabular}

Napomena: ${ }^{*}$ - $p<0,05,{ }^{* *}$ - $p<0,01$

Analiza podataka ANOVA je potvrdila da postoje statističke razlike između dužine reznica, kod kojih je $\mathrm{p}<0,05$.

Dužina bočnih korjenova iskazala je statističke razlike na oba nivoa značajnosti $(\mathrm{p}<0,05$ i $\mathrm{p}<0,01)$ između reznica kod tri hormonalna tretmana: IAA i NAA kod reznica bez povrede te reznica bez hormona sa povredom, što je predstavljeno u tabeli 4. 


\section{Indukcija rizogeneze kod crne ribizle (Ribes nigrum L.)}

Analizom podataka pomoću ANOVA-e potvđeno je da postoje statitički značajne razlike između reznica na nivou značajnosti $p<0,05$. Najviše statistički značajnih razlika za svojstvo debljine bočnih korjenova između jedinki unutar istih hormonalnih tretmana zabilježeno je skoro kod svih tretmana. Jedini hormonalni tretman koji nije iskazao statistički značajne razlike između pojedinih reznica $u$ tretmanu je NAA kod reznica sa povredom.

Za svojstvo broja korjenova drugog reda statistički značajne razlike, između jedinki kod jednog hormonalnog tretmana, iskazane su na oba nivoa značajnosti $(\mathrm{p}<0,05 \mathrm{i} \mathrm{p}<0,01$, $\mathrm{i}$ to kod hormonalnih tretmana IBA reznice sa povredom), IAA (reznice sa povredom), NAA (reznice sa povredom), NAA (reznice bez povrede) i kontrolne grupe (reznice sa i bez povrede).

U narednim analizama se pomoću rezultata dobivenih Fisherovim multiplim testovima (LSD), na nivou značajnosti $\mathrm{p}<0,05$ i p $<0,01$, konstruirala tabela $5 \mathrm{u}$ kojoj su predstavljene statistički značajne razlike za istraživanu karakteristiku korjenova ožiljenih reznica tretiranih različitim hormonalnim tretmanom, kao i kontrolnih reznica.

Za svojstvo dužine bočnih korjenova hormonalni tretman NAA kod reznica bez povrede iskazao je statistički značajne razlike na između svih ostalih hormonalnih tretmana (između 7 tretmana), zatim slijede hormonalni tretman IAA (reznice sa povredom) i kontrolne reznice bez povrede (između 6 tretmana), a nakon njih IBA sa povredom i bez povrede reznica, NAA sa povredom reznica i kontrola sa povredom reznica (između 4 tretmana), što je prikazano u tabeli 5.

Tabela 5. Statistički značajne razlike dužine bočnih korjenova kod reznica tretiranih različitim tretmanom.

Table 5. Significant difference in the length of lateral roots of the cuttings treated with different treatments.

\begin{tabular}{|c|c|c|c|c|c|c|c|}
\hline Tretmani & IBA-P & IBA-BP & IAA-P & IAA-BP & NAA-P & NAA -BP & Kontrola-P \\
\hline IBA-BP & 0.2844 & & & & & & \\
\hline IAA-P & $\mathbf{0 . 0 0 9 8 * *}$ & $\mathbf{0 . 0 0 0 3 * *}$ & & & & & \\
\hline IAA-BP & 0.4790 & 0.7097 & $\mathbf{0 . 0 0 1 0 * *}$ & & & & \\
\hline NAA-P & $\mathbf{0 . 0 3 4 1 *}$ & 0.2811 & $\mathbf{0 . 0 0 0 0 * *}$ & 0.1472 & & & \\
\hline NAA -BP & $\mathbf{0 . 0 0 0 0 * *}$ & $\mathbf{0 . 0 0 0 0 * *}$ & $\mathbf{0 . 0 0 0 0 * *}$ & $\mathbf{0 . 0 0 0 0 * *}$ & $\mathbf{0 . 0 0 0 0 * *}$ & & \\
\hline Kontrola-P & 0.2316 & $\mathbf{0 . 0 2 9 1 *}$ & 0.2198 & 0.0634 & $\mathbf{0 . 0 0 1 8 * *}$ & $\mathbf{0 . 0 0 0 0 * *}$ & \\
\hline Kontrola-BP & $\mathbf{0 . 0 0 2 2 * *}$ & $\mathbf{0 . 0 3 6 6 *}$ & $\mathbf{0 . 0 0 0 0 * *}$ & $\mathbf{0 . 0 1 4 4 *}$ & 0.2919 & $\mathbf{0 . 0 0 1 1 * *}$ & $\mathbf{0 . 0 0 0 1 * *}$ \\
\hline
\end{tabular}

Napomena: * $-\mathrm{p}<0,05,{ }^{* *}$ - $\mathrm{p}<0,01 ; \mathbf{P}$-sa povredom; BP-bez povrede. 
Za svojstvo debljine bočnih korjenova hormonalni tretmani IBA i NAA (kod reznica sa povredom) i kontrolnih reznica (sa i bez povrede) iskazali su statistički značajne razlike na oba nivoa značajnosti između svih ostalih hormonalnih tretmana $i$ reznica koje su postavljene kao kontrola, zatim slijede hormonalni tretmani IBA i NAA (reznice bez povrede) i IAA (reznice sa i bez povrede).

$\mathrm{Za}$ svojstvo broja korjenova drugog reda hormonalni tretmani IBA, NAA i kontrolne reznice (bez povrede) iskazali su najviše statistički značajnih razlika na oba nivoa značajnosti između ostalih hormonalnih tretmana i reznica koje su postavljene kao kontrola, zatim slijedi hormonalni tretman IAA kod reznica bez povrede, nakon toga tretmani IAA, NAA i kontrolne reznice (sa povredom), dok je najmanje statističkih razlika pokazao hormonalni tretman IBA kod reznica sa povredom.

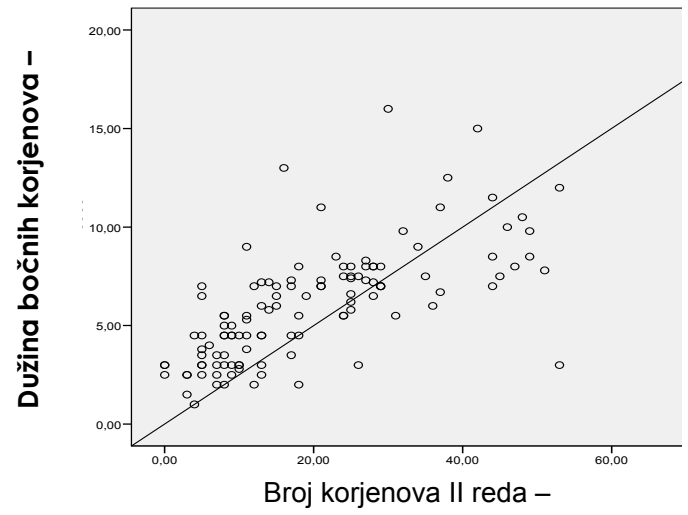

Grafikon 4. Pozitivna korelacija

$\mathrm{U}$ daljim se analizama korištenjem koeficijenta korelacije $\mathrm{r}$ pokušalo ustanoviti da li unutar proučavanih hormonalnih tretmana postoji određena povezanost između pojedinih istraživanih parametara reznica (dužina bočnih korjenova, debljina bočnih korjenova, broj korjenova II reda).

Istraživanje je rađeno međusobnom usporedbom parametara reznica.

Određeni komparirani parovi iskazali su visoke vrijednosti koeficijenta korelacije, što govori da su posmatrana svojstva u pozitivnoj korelaciji (grafikon 4), tj. porast vrijednosti jedne varijable uzrokuje i rast druge.

\section{ZAKLJUČCI - Conclusions}

Analize dobivenih podataka pokazale su kako se kao najvarijabilniji karakter kod istraživanih jedinki unutar istog hormonalnog tretmana javlja broj korjenova II reda, a debljina bočnih korjenova je karakter koji je iskazao najveći broj statistički značajnih razlika između kompariranih tretmana.

Analizom varijanse (ANOVA) konstatirane su statistički značajne razlike, kako između jedinki unutar jednog hormonalnog tretmana, tako i između tretmana.

Pomoću LSD i Fisherovih testova testova utvrđeno je da hormonalni tretman NAA kod reznica bez povrede iskazuje najveći broj statistički značajnih razlika na oba nivoa značajnosti između kompariranih jedinki, kao i kod kompariranih tretmana.

Iz navedenih rezultata najbolji hormonalni tretman za indukciju rizogeneze crne ribizle pokazao se IAA, i to kod reznica sa povredom, što se podudara sa dostupnim podacima drugih istraživača. 


\section{Indukcija rizogeneze kod crne ribizle (Ribes nigrum L.)}

Rezultati ovih istraživanja mogu poslužiti kao dobra osnova za odabir tretmana koji je najpovoljniji i koji daje nabolje rezultate u masovnoj proizvodni ove vrste.

Prema broju razvijenih korjenova te njihovoj dužini, debljini, broju korjenova II reda i ukupnom porastu ožiljene reznice ribizle u potpunosti zadovoljavaju kriterije kvalitete sadnog materijala, koji se uz dodatno „školovanje” od jedne godine može iznositi u vrt.

\section{LITERATURA - References}

GRBIĆ, M. (2004): Vegetativno razmnožavanje ukrasnog drveća i žbunja, Beograd. HESSAYON, D.G. (2001): Cvatući grmovi, Mozaik knjiga, Zagreb.

Jovanović, B. (2000): Dendrologija, Univerzitetska štampa, Beograd.

KuRtović, M., Gašl, F., DRkEnda, P., HadžIABUlić, S. (2003): Jagodasto voće ProzorRama: Natura Ramae, Sarajevo.

LJUJIĆ-MIJATOVIĆ, T., MRDović, A. (1998): Proizvodnja cvijeća i ukrasnog bilja, Univerzitet u Sarajevu, Sarajevo

MEĐEdović, S. (1987): Ožiljavanje reznica smrče u cilju razvijanja tehnologije masovne proizvodnje sadnica, Šumarstvo i prerada drveta, Sarajevo. 1-3: 27 - 33.

Męedović, S., FeRHATOVIĆ, DŽ. (2003): Klonska proizvodnja sadnica drveća i grmlja, BEMUST, Sarajevo.

MEKIĆ, F. (1998): Uzgajanje i umnožavanje drveća i grmlja, Šumarski fakultet, Sarajevo.

\section{SAŽETAK - Summary}

Black currant (Ribes nigrum L.) is the species with the common usage in the horticulture in different ways due to its significant decoration attributes, as selfcontained bush or as a hedge. Because of its quality and nutritious fruits, black currant is often raised in gardens as berry fruits.

This study elaborates rizogenesis of black currant, and it implies the possibility of mass production by means of vegetative reproduction, with usage of ripe cuttings. Furthermore, it showed influence of the affected cuttings and different hormonal treatments on the risogenesis induction, on a number of cuttings and on the quality of the root system (length and thickness of the lateral roots and the number of second line roots).

The cuttings were treated with three types of plant hormones (IAA, IBA, and NAA) in a mould form, in addition to the control group, without hormonal treatment.

In this study, the total sample was 110 cuttings, with 55 affected cuttings (sharpened $1,5 \mathrm{~cm}$ above the base of cuttings), and 55 cuttings without harm. Therefore, 30 cuttings ( 15 with and 15 without harm) were treated with hormones, and 20 cuttings (10 with and 10 without harm) were used as a control group, without hormonal treatment.

The cuttings were raised in containers with the mixture substrate of sphagnum and sand, in 3:1 ratio. 
After 3 months, the cuttings were pulled out from the mixture substrate and measurements were done. The arithmetic mean value of the length of the lateral roots was the highest in the group with IAA hormonal treatment $(7,251 \mathrm{~cm}$ for affected cuttings), and the lowest value was in the group with NAA hormonal treatment $(4,019$ $\mathrm{cm}$ no affected cuttings).

The highest arithmetic mean value for the thickness of lateral roots was in the group with NAA hormonal treatment $(0,793 \mathrm{~mm}$ for affected cuttings), and the lowest value was in the control group (non-affected cuttings: $0,272 \mathrm{~mm}$ ).

The arithmetic mean value for the number of roots, at the second line of roots, was noticed at the affected cuttings with IAA hormonal treatment (26,661 roots), while the smallest number was in the non-affected control group of cuttings $(7,252$ roots per individual).

From the denominated results, the best hormonal treatment for risogenesis induction of black currant was with IAA for the affected cuttings, which coincides with the available sources reported by other researchers. 